NASA Contractor Report 191108

\title{
Electrical Characterization of a Space Station Freedom Alpha Utility Transfer Assembly
}

Edward J. Yenni

Rockwell International

Fairview Park, Ohio

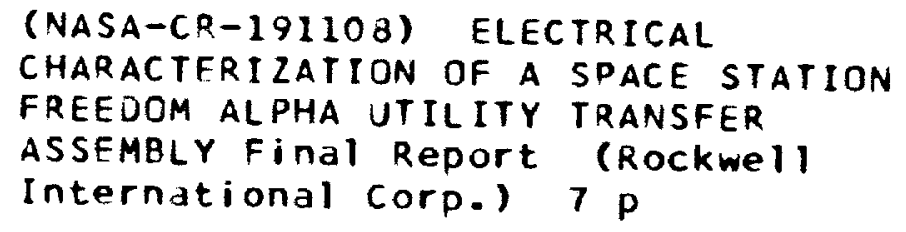

February 1994

Prepared for

Lewis Research Center

Under Contract NAS3-25711

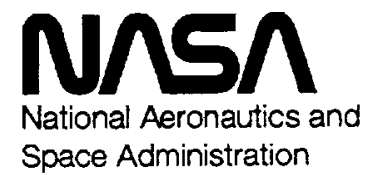




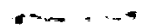

*

- 


\title{
ELECTRICAL CHARACTERIZATION OF A SPACE STATION FREEDOM
}

\section{ALPHA UTILITY TRANSFER ASSEMBLY}

\author{
Edward J. Yenni \\ Rockwell International \\ Rocketdyne Division \\ Fairview Park, Ohio 44126
}

\begin{abstract}
Electrical power, command signals and data are transferred across the Space Station Freedom solar alpha rotary joint by roll rings, which are incorporated within the Utility Transfer Assembly (UTA) designed and manufactured by Honeywell Space Systems Operations. A developmental model of the UTA was tested at the NASA Lewis Research Center using the Power Management and Distribution DC test bed. The objectives of these tests were to obtain data for calibrating system models and to support final design of qualification and flight units. This testing marked the first time the UTA was operated at high power levels and exposed to electrical conditions similar to that which it will encounter on the actual Space Station. Satisfactory UTA system performance was demonstrated within the scope of this testing.
\end{abstract}

\section{INTRODUCTION}

The Space Station Freedom's alpha and beta gimbals position the solar arrays to track the sun as the station orbits the earth. Electrical power, command signals and data are transferred across the solar alpha rotary joint by roll rings, a Honeywell patented design, which are incorporated within the Utility Transfer Assembly (UTA) designed and manufactured by Honeywell Space Systems Operations. The UTA's characteristics and interaction with the primary power distribution network are of considerable interest to designers of the electrical power system. This paper summarizes electrical testing of a UTA developmental unit performed from January 22 through February 25, 1992 at the NASA Lewis Research Center (LeRC) using the Power Management and Distribution (PMAD) DC test bed.

The objective of this testing was not to verify compliance to a particular specification per se, but primarily to quantify the UTA's basic electrical characteristics and investigate its interaction with electrical power similar to that which it will encounter on the actual Space Station. Consequently, specific pass/fail criteria have not been levied, however the results are provided for calibrating system models and to support final design of qualification and flight units.
This testing marked the first time the UTA was operated at high power levels and subjected to system-like electrical power conditions. Satisfactory UTA system performance was demonstrated within the scope of this testing, which included exposing the UTA to normal operational voltage and current transients while an adjacent channel configured with a MII STD-1553 data bus was monitored for induced errors. A prototype Space Station Data Management System kit was used to simulate a MIL - STD-1553 bus controller and remote terminal for these tests.

The scope of this testing emphasized those activities which made use of the unique facilities available at LeRC. A detailed description of the UTA developmental unit and test apparatus, summary level test results and concluding remarks are presented attendant to the following:

- Electrical Transfer Efficiency

- Crossing Impedance

- Electrical Rolling Noise

- Corona Onset Voltage

- Coupling Between Power and Signal Crossings

- Transient Voltage and Current Response

\section{TEST ARTICLE AND SUPPORT FACILITY}

UTA DESCRIPTION - The UTA tested was a developmental unit which features 24 power crossings and 48 signal crossings, where a crossing is defined as an electrical path from rotating (rotor) to stationary (stator) side. The UTA measures approximately 1.2 meters in length and $76 \mathrm{~cm}$ in diameter at the stator end and weighs $125 \mathrm{~kg}$. Dual resolvers accurate to within $1 / 10$ of a degree are provided to indicate rotor position. Redundant bearings activated by shear pins were designed to switch rotation from primary to secondary bearing if drag torque increases above $2.7 \mathrm{~N}-\mathrm{m}$. 
Power Crossings - Each of the 24 power crossings consists of fourteen flexures, fourteen idlers, an inner and outer contact ring, and two rim rollers. The fourtcen flexures are captured in the annular space between the inner and outer contact rings, with an idler positioned between every flexure. Power is transferred from the inner contact ring through the flexures to the outer contact ring. The purpose of the idlers, which are captured by the rim rollers, is to maintain a minimum distance from flexure to flexure. Each power crossing is rated for 200 Amps steady state at 160 VDC and contributes less than $1.1 \times 10-2 \mathrm{~N}-\mathrm{m}$ of drag torque.

Five foot pigtails of highly stranded and flexible $1 / 0 \mathrm{AWG}$ cables are connected to each power crossing's stator connector. The rotor connectors are jumpered together with cables cut to length and of the same 1/0 AWG cable as the pigtails. This configuration permits a continuous rotation of the unit without cable binding. The crossings jumpered together at the rotor end of UTA were chosen to maintain a one crossing separation between hot and return.

Signal Crossings - The UTA incorporates four, 24-crossing signal modules with each crossing containing a single flexure. Redundancy is provided by paralleling two crossings, resulting in a total of 48 available crossings rated for 10 Amps steady state at 120 VDC. The signal crossings are grouped in threes, high, low and shield, and connected to standard MII-STD-1553 twinaxial cable. Shields are tied to the case at both the rotor and stator and are also carried through using individual crossings. The signal crossing's rotor connectors are also jumpered to allow continuous rotor rotation.

\section{INSTRUMENTS AND ENVIRONMENT -}

Vacuum Facility - All high power testing of the UTA was conducted in a high vacuum. The base of the vacuum tank measured approximately $1.2 \mathrm{~m}$ high and $1.5 \mathrm{~m}$ in diameter. The base provided ports for feedthrough of power, control and instrumentation, with a $54 \mathrm{~cm}$ port provided for the cryopump. A cylindrical lid approximately $2.4 \mathrm{~m}$ long was handled by overhead crane and covered the base. The chamber attained a pressure of $6.7 \mu \mathrm{Pa}$ when empty and with the addition of the test article, reached the low 133 to $13 \mu \mathrm{Pa}$ range after a 24 hour outgassing interval.

Test Stand - A test stand was fabricated for the UTA to orient the unit vertically in the vacuum tank with the rotor end down. The test stand was fastened to cross braces in the center of the vacuum chamber base. A vacuum rated, two-phase hybrid permanent magnet stepper motor was used to drive the UTA rotor at a four degree per minute rate. This equates to one revolution per 90 minutes, the actual rate it will rotate on the Space Station. The UTA rotor was connected to a $46 \mathrm{~cm}$ angular contact bearing incorporated in the test stand. The stepper motor was coupled to the contact bearing through a 200:1 gear reduction box and instrumented with a torque sensor to monitor drag torque for unsafe levels.
The average rotor drag torque experienced during testing remained at a constant $1.13 \mathrm{~N}-\mathrm{m}$. Approximately $60 \%$ of the drag torque is acquired from the test fixture bearing, $22.5 \%$ from the power roll rings and $17.5 \%$ from the UTA bearings. The contribution from the signal roll rings is negligible.

Instrumentation - Voltage sense lines were provided from each power crossing's stator connector solder pot alóng with the $1 / 0$ AWG pigtails. Since the corresponding rotor connectors are jumpered to allow for continuous rotation, the stator sense wires provide the voltage dropped across two series connections. For this reason, some test results are provided for two series-connected crossings instead of a single crossing.

Approximately $1.5 \mathrm{~m}$ of twinaxial cable was connected to each signal crossing and was routed through the stator housing. The cables were fed to a breakout box which provided connectors for the crossing triplets and was mounted to the test stand. The UTA was instrumented with thermocouples and resistive temperature devices in key locations internal and external to the UTA to monitor for dangerous thermal conditions.

The power, instrumentation and control cables were passed through the vacuum tank wall on bulkheads fitted with vacuum feedthroughs. The power feedthroughs were $0.95 \mathrm{~cm}$ diameter copper rods rated at 250 Amps at $3 \mathrm{kV} \mathrm{DC}$. Signal crossing feedthroughs were designed for MIL-STD-1553 use and therefore provided minimal disnuption to the bus impedance.

A test fixture was used to sense the voltage drop for each pair of power crossings, indicate and record rotor position, and monitor the temperature sensors for unsafe conditions. The fixture also provided MIL-STD-1553 source and error detection hardware.

Transfer efficiency, crossing impedance, electrical rolling noise and coupling tests were all performed in atmosphere with the unit installed in the test stand. Electrical rolling noise, MII-STD-1553 data bus bit error rate and PMAD test bed transients were the only tests for which the rotor was turning.

\section{SUMMARY OF RESULTS}

ELECTRICAL TRANSFER EFFICIENCY - High UTA electrical transfer efficiency is desirable for the Space Station Freedom application to minimize heat load on the thermal control system and deliver maximum power to connected loads. The DC, or static, transfer resistance of UTA power and signal crossings was determined by performing a "four wire" measurement. A known value of current was conducted through each crossing and the corresponding voltage drop was measured with a millivolt meter. The derived static resistance was then computed for each crossing using Ohm's law.

Power Crossings - A 50 Amp current source was used for the measurements to derive power crossing $D C$ resistance. The voltage drop was measured by probing the rotor and stator connectors through insulating boots. The derived resistance is for a single rotor to stator transition and does not include connector 
resistance. The average power crossing static resistance was determined to be 0.84 milliohms.

The total calculated UTA heat loss from the power crossings is therefore:

$\mathrm{P}=\left[2 \mathrm{R},(45 \mathrm{amps})^{2} \times 0.8 \mathrm{~m} \Omega \times 24\right.$ crossings $=39$ Watts.

Signal Crossings - The signal crossing DC resistance measurements were performed at 10 amps and on two crossings connected in series, since the power crossing's rotor jumper plate prohibited easy access to the signal crossing rotor connectors. In addition, the measurements include the resistance of approximately $1.5 \mathrm{~m}$ of twinaxial cable connected to each stator for a total of $3 \mathrm{~m}$. The measurements were performed with 5 Amps of source current. The static resistance for two series-connected signal crossings averaged 686 milliohms. Approximately 100 milliohms of the resistance can be attributed to the $3 \mathrm{~m}$ of external pigtails.

IMPEDANCE - Considerable effort is being made to minimize impedances in the Space Station primary power distribution network to improve transient performance, therefore making the UTA's total impedance contribution of significant interest. The impedance of the UTA's power and signal crossings was measured using two different techniques. The bulk of these measurements were made using an autobalancing bridge, while some measurements relied on a network analyzer driving external high power amplifiers as a means of excitation.

Autobalancing Bridge Measurements - A Hewlett-Packard 4274A Multi-Frequency LCR Meter was used to perform power and signal crossing impedance measurements. This meter is an autobalancing bridge type of instrument that has been used successfully in the past to measure low impedances [1]. Some of the impedance configurations tested required reconfiguration of the rotor jumpers. A bolt-on set of custom measurement leads were used with the instrument and connected in a modified four-terminal (Kelvin) configuration. Open and short compensation of the probe was performed prior to each series of measurements to calibrate out residuals.

UTA power crossings are stacked in layers and for the purposes of this paper have been numbered 1 through 24 . Every other crossing was jumpered together at the rotor to maintain a one crossing separation between hot and return. The corresponding stator connectors for these crossings are either 120 or 135 degrees apart on the $76 \mathrm{~cm}$ stator connector plate, so the pigtails were tied to minimize the total loop area of the connection prior to each measurement being performed. Power and signal crossing assignments tested may not reflect the final configuration for the Space Station application, which is the primary reason data are provided for various configurations. Paralleled circuit configurations, two hots/two returns, were tested with the hot leads maintained at the comers of the cable bundle.

The classical model of a transmission line, a series inductance and resistance with a shunt capacitance, was assumed to be an adequate representation for UTA circuits. Inductance was determined by performing a short circuit measurement, with the short provided by the rotor jumper connector. The rotor jumper was removed to perform an open circuit measurement of capacitance. The inpedance measurements are summarized in the tables below.

Powtr Crossing inductance (ut)

\begin{tabular}{|c|c|c|c|c|c|}
\hline CAOSSING PAR & $100 \mathrm{~Hz}$ & $1 \mathrm{kHz}$ & $10 \times 12$ & $20 \mathrm{XHz}$ & $100 \mathrm{KHz}$ \\
\hline 1703 & 3.1 & 2.8 & 25 & 24 & 2.3 \\
\hline 2704 & 3.4 & 3 & 28 & 26 & 2.6 \\
\hline 5707 & 3.3 & 27 & 25 & 24 & 23 \\
\hline 6708 & 3.2 & 28 & 25 & 24 & 2.3 \\
\hline 9TO 11 & 3.2 & 28 & 26 & 25 & 24 \\
\hline 10 TO 12 & 3.2 & 29 & 28 & 25 & 24 \\
\hline 137015 & 3 & 27 & 24 & 23 & 23 \\
\hline 147016 & 29 & 27 & 25 & 24 & 23 \\
\hline 177019 & 3.1 & 27 & 25 & 24 & 23 \\
\hline $18 T 020$ & 3 & 2.8 & 25 & 24 & 24 \\
\hline 217023 & 3.2 & 2.9 & 28 & 25 & 24 \\
\hline 221024 & 3.2 & 28 & 25 & 24 & 24 \\
\hline AVG 1PA VALUE & 3.2 & 28 & 25 & 24 & 24 \\
\hline MLX IPA YALUE & 3.4 & 3 & 28 & 26 & 26 \\
\hline ENA IPR VALUE & 29 & 27 & 24 & 23 & 23 \\
\hline \multicolumn{6}{|l|}{ MASC CONFIG } \\
\hline 1507 & 28 & 23 & 24 & 23 & 22 \\
\hline $1 \mathrm{TO} 13$ & 29 & 26 & 24 & 24 & 23 \\
\hline 17024 & 28 & 25 & 23 & 22 & 22 \\
\hline 13 TO 14 & 33 & 28 & 28 & 25 & 25 \\
\hline PARALLELED COANFG & SEE BELOW' & & & & \\
\hline & & & & & \\
\hline ITHAU $(\omega \cdots)$ & 22 & 2 & 18 & 1.8 & 1.7 \\
\hline 1TRAU4 $(-\cdot+)$ & 22 & 1.7 & 1.6 & 1.6 & 1.5 \\
\hline 1THAU4 $(t-t)$ & 1.7 & 1.4 & 13 & 13 & 1.3 \\
\hline
\end{tabular}

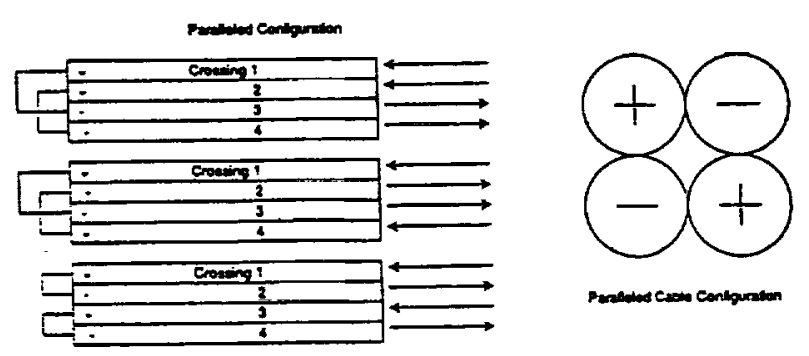

Power Crossing Capaciance (of)

\begin{tabular}{|c|c|c|c|c|c|}
\hline CAOSSING PAR & $100 \mathrm{~Hz}$ & $1 \mathrm{KHz}$ & 1010tz & 40 KOHI & $100 \mathrm{KHE}$ \\
\hline 17024 & 491 & 470 & 180 & 180 & 400 \\
\hline $18 T 024$ & 90 & 91 & $x$ & 2 & 92 \\
\hline 24 TO CASE & 469 & 467 & 465 & 403 & 462 \\
\hline
\end{tabular}

Sippal Crossing Charactoristics

\begin{tabular}{|c|c|c|c|c|c|}
\hline & $100 \mathrm{~Hz}$ & $1 \mathrm{KHz}$ & $10 \mathrm{kgt}$ & $40 \mathrm{kt}$ & $100 \mathrm{ktz}$ \\
\hline & & & & & \\
\hline MOUCTAKCE & (w) & & & & \\
\hline & & & & & \\
\hline SHELLD TO MIGH & 1.8 & 1.8 & 1.5 & 1.1 & 1 \\
\hline HIGH TO LOW & 1.7 & 1.7 & 1.7 & 1.6 & 1.4 \\
\hline & & & & & \\
\hline CAPACT ANCE & $\overline{p r}$ & & & & \\
\hline & & & & & \\
\hline SHIELO TO HIGH & 300 & 350 & 347 & 345 & 303 \\
\hline HOGH TOLOW & 9 & 92 & 9 & 0 & 91 \\
\hline
\end{tabular}


Network Analvzer/Power Amp Measurements - A Hewlett-Packard 3577A Network Analyzer was used in conjunction with a high power amplifier to obtain a gain-phase plot of the UTA circuit response. Current was measured with a clamp on probe connected to a current probe amplifier and voltage was measured through a voltage isolator.

The test results using this technique were found to agree closely with the autobalancing bridge method, so only the autobalancing bridge measurements have been presented here.

ELECTRICAL ROLLING NOISE - The purpose of this test was to characterize the electrical noise generated by crossing resistance variations that occur as the UTA rotor moves. These variations could result in noise being introduced into the power circuits, or data dropouts in the signal circuits and is caused by the rolling motion of the flexures against the inner and outer conducting rings. The power crossings each consist of 14 separate flexures, while each signal crossing contains two. The flexures can be considered as separate variable resistances operating in parallel. The effect of the number of conducting flexures on rolling noise was evident from the higher noise detected from the signal crossings.

A power supply with a large external series resistance was connected to a pair of crossings with an oscilloscope used to monitor voltage fluctuations. Since the measured voltage is proportional to the crossing current and the crossing resistance, the $\mathrm{AC}$ component represents the noise voltage.

The initial noise readings were obscured by noise radiated from the stepper motor driving the UTA rotor. This noise spectrum was in the several $\mathrm{kHz}$ range, and was reduced by a low pass filter at the scope input. In both tests, the noise was not discemible with the rotor turning at the 4 degree per minute rate. Rolling noise did become apparent though as the speed of rotation was increased by about a factor of three. These measurements are for two crossings connected in series.

Pewer Crossings - The power crossing measurements were performed with 42 Amps of current and a single-pole $100 \mathrm{kHz}$ low pass filter at the scope input. The rolling noise was found to be less than 1 millivolt, equating to about 24 microohms of modulation resistance.

Signal Crossings - The signal crossing measurements were performed with $1.8 \mathrm{Amps}$ of current and a single-pole $10 \mathrm{kHz}$ low pass filter at the scope input. Approximately 0.5 millivolts of rolling noise was measured, equating to about 0.3 milliohms of modulation resistance.

CORONA ONSET VOLTAGE - Corona tests were performed on the UTA to verify its ability to operate at the 160 volt nominal distribution voltage. The corona tester applies a high voltage $60 \mathrm{~Hz}$ signal, and indicates partial discharge on an oscilloscope, with discharges of a few picocoulombs being readily apparent. For these tests, the applied voltage was slowly increased until corona was observed. Only the discharge level in volts was recorded and not the discharge magnitude.
Two sets of tests were conducted, the first with the UTA in atmosphere and the second with the UTA under vacuum. The tests in atmosphere were conducted with the power crossing cables isolated in mid air and free from connectors, terminal strips, or feedthroughs. The power crossing voltage sense wires were also disconnected. The UTA housing and all remaining crossings except the crossings under test were grounded. This configuration was chosen to most accurately represent the Space Station electrical power system and test the UTA itself, without the influence of external circuits. Three pairs of series connected crossings were tested one pair at a time. The selected crossings represented pairs from each end of the UTA's power can and a pair in the center.

Following are the values of corona onset for the power crossings:

\begin{tabular}{ll} 
Crossing Pair & Corona Onset \\
\hline 1 and 3 & 1200 Volts \\
9 and 11 & 1050 Volts \\
22 and 24 & 1100 Volts
\end{tabular}

The signal rings are also designed to be used for control power, and therefore may be exposed to a nominal $160 \mathrm{VDC}$. Only two pairs of signal rings were tested, due to the difficulty of isolating these crossings, and consequently were tested with the external wiring and connectors in place. The connectors were common triaxial types. The corona onset voltage for the two signal crossing pairs tested was approximately 1100 VDC.

The second set of tests were conducted with the UTA under vacuum environment, at a pressure of about $93 \mu \mathrm{Pa}$. The power crossings were connected via feedthroughs with a corona onset above $4 \mathrm{kV}$. However, the voltage sense leads disconnected in the first series of tests were left connected for system monitoring terminating in a feedthrough connector, with the end open to atmosphere. The corona onset was measured between 1100 and 1200 VDC. The voltage was probably limited by the test connector, but was high enough that further testing without the test connector was determined to be unnecessary. Tests of the control signal crossings, with the $1553 \mathrm{~B}$ cable and connectors and feedthroughs in place yielded an onset of 1100 VDC.

COUPLING BETWEEN CROSSINGS - This test investigated coupling between power-signal and signal-signal crossings. Coupling was measured by exciting a crossing circuit with a large sinusoidal waveform while monitoring a terminated crossing in close physical proximity. Sinusoidal currents were used to measure inductive coupling and large voltages were used for capacitive coupling. The primary means of coupling was determined to be capacitive.

Crosstalk between power and signal crossings was measured with the signal crossing terminated using a MIL-STD-1553 bus terminator. Power-signal crossing coupling was measured to be $-67 \mathrm{~dB}$ at $1 \mathrm{MHz}$. Signal-signal coupling was measured to be -71 $\mathrm{dB}$ at $1 \mathrm{MHz}$.

PMAD TEST BED TRANSIENT RESPONSE - The objective of this test was to demonstrate the UTA's capability to withstand normal PMAD test bed voltage and current transients 
and ensure coupling of these events into the signal crossings is insufficient to cause bit errors in an active MIL-STD-1553 data bus. PMAD test bed ground fault transients were not included as part of this investigation.

System Confiquration - The UTA was cabled to the PMAD test bed between the Direct Current Switching Unit (DCSU) and Main Bus Switching Unit (MBSU) in the center of approximately 220 feet of paralleled ( 2 hots $/ 2$ returns) $1 / 0$ power cable that was closely coupled and shielded by a metallic zipper wrap. The DCSU and MBSU bus capacitances, $1140 \mu \mathrm{F}$ and $875 \mu \mathrm{F}$ respectively, were derived to represent the baseline values for the Space Station design at the time these tests were performed. This included total snubber capacitance for each unit. The actual values were the closest values that could be obtained from available $84.6 \mu \mathrm{F}$ ceramic modules.

MILSTD-1553 Data Bus - The MIL_STD-1553 test setup consisted of a DDC BUS- 65517 bus controller card installed in a Space Station Data Management System (DMS) prototype kit. The remote terminal was also a BUS-65517 card installed in a 386 personal computer. Software resident in the remote terminal captured data from the bus monitor and calculated bit error rate after each transient test [2].

The DMS kit software provides an adjustable data bus transmission voltage. Several tests were performed while lowering the transmission voltage to determine the level at which error onset began. As a worst case scenario, one step above this level was used to test for transient induced errors.

Transient Testing - The following test bed operational transients were performed:

- DCSU Bus Energization

- MBSU Bus Energization

- DDCU Energization

- DDCU De-energization - $9 \mathrm{~kW}$ Load Shed

No data bus errors were recorded for any of the transient test cases.

\section{CONCLUSIONS}

In summary, the UTA developmental unit testing performed at LeRC accomplished all of the goals established for this effort with no major problems having been identified. The testing yielded valuable information to support calibration of system models and to aid in finalizing the UTA design for subsequent qualification and flight units.

The DC resistance and steady state temperatures recorded are evidence of the UTA's high electrical transfer efficiency. The thermal interface between the Space Station primary power distribution cables operating at predicted temperature extremes and the UTA was not verified, as further analysis and facility modifications would be required to support such a test. The impedance test results suggest the total inductance of a UTA crossing pair is substantially higher than originally specified in the Space Station Electrical Power System Architectural Control Document and consequently should be considered in the design of the primary distribution network. Electrical rolling noise was shown to be extremely low in magnitude, possibly to the point it could be neglected in simulation and modeling efforts.

Corona test results indicate no inherent problém with this particular UTA design. Since the onset of corona is very much dependent on geometry, successful results for this testing do not necessarily guarantee that subsequent designs will comply with corona specifications. The corona results are believed to be conservative because the corona onset probably occurred in the external circuitry instead of within the UTA, especially for the testing under vacuum. Onset values above $1 \mathrm{kV}$ would seem sufficient for the Space Station application.

The primary mode of crosstalk coupling was determined to be capacitive and appears to be sufficiently attenuated so that power transients do not cause disruption to the MIL-STD-1553 data bus. The post-test performance measurements demonstrated the unit did not suffer adverse effects from exposure to normal system transients. Off-normal transients were not investigated however, and would be a logical follow on activity to the testing reported on here.

\section{REFERENCES}

[1] Yenni, E. J. and Brush, A. S., "Power Cable Impedance Characterization," NASA Lewis Research Center Electrical Systems Division Preliminary Test Report \#6.

[2] Gantose, D. L., Sverdrup Technology, Inc. "MIISTD-1553B Communications Test Program for the Alpha Utility Transfer Assembly." NASA LeRC Preliminary Information Report \#267. 
Public reporting burden for this collection of information is estimated to average 1 hour per response, including the time for reviewing instructions, searching existing data sources, gathering and maintaining the data needed, and completing and reviewing the collection of intormation. Send comrients regarding this burden estimate or any other aspect of this collection of infomation, including suggestions for reducing this burden, to Washington Headquarters Services, Directorate for information Operations and Reponts. 1215 Jefferson Davis Highway, Suite 1204, Artington, VA 22202-4302, and to the Office of Management and Gudget. Papework Reduction Project (0704-0188), Washington, DC 20503.

\begin{tabular}{|l|c|c|}
\hline 1. AGENCY USE ONLY (Leave blank) & $\begin{array}{c}\text { 2. REPORT DATE } \\
\text { February } 1994\end{array}$ & $\begin{array}{r}\text { 3. REPOAT TYPE AND DATES COVERED } \\
\text { Final Contractor Report }\end{array}$
\end{tabular}

\section{TITLE AND SUBTITLE}

Electrical Characterization of a Space Station Freedom Alpha

Utility Transfer Assembly

6. AUTHOR(S)

Edward J. Yenni

5. FUNDING NUMBERS

WU-474-42-10

C-NAS3-25711

7. PERFORMING ORGANIZATION NAME(S) AND ADDRESS(ES)

Rockwell International

Rocketdyne Division

22021 Brookpark Road

Fairview Park, Ohio 44126

9. SPONSORINGMONITORING AGENCY NAMES(S) AND ADDRESS(ES)

National Aeronautics and Space Administration

Lewis Research Center

Cleveland, Ohio 44135-3191

8. PERFORMING ORGANIZATION REPORT NUMBER

$\mathrm{E}-7715$

10. SPONSORINGMONITORING AGENCY REPORT NUMBER

NASA CR-191108

11. SUPPLEMENTARY NOTES

Prepared for the 27th Intersociety Energy Conversion Engineering Conference sponsored by the SAE, ACS, AIAA, ASME, IEEE, AIChE, and ANS, San Diego, California, August 3-6, 1992. Project Manager, A. Baez, Electrical Systems Division, organization code 8840, (216) 433-5318.

12a. DISTRIBUTIONAVAILABILITY STATEMENT 12b. DISTRIBUTION CODE

Unclassified - Unlimited

Subject Category 20

\section{ABSTRACT (Maximum 200 words)}

Electrical power, command signals and data are transferred across the Space Station Freedom solar alpha rotary joint by roll rings, which are incorporated within the Utility Transfer Assembly (UTA) designed and manufactured by Honeywell Space Systems Operations. A developmental Model of the UTA was tested at the NASA Lewis Research Center using the Power Management and Distribution DC test bed. The objectives of these tests were to obtain data for calibrating system models and to support final design of qualification and flight units. This testing marked the first time the UTA was operated at high power levels and exposed to electrical conditions similar to that which it will encounter on the actual Space Station. Satisfactory UTA system performance was demonstrated within the scope of this testing.

\section{SUBJECT TERMS}

Roll rings; Solar alpha rotary joint; Power management and distribution

$$
\text { Roll rings; Solar alpha rotary joint, Power management and distribution }
$$

17. SECURITY CLASSIFICATION OF REPORT

Unclassified

18. SECURITY CLASSIFICATION OF THIS PAGE Unclassified
19. SECURITY CLASSIFCATION OF ABSTRACT Unclassified 